\title{
INTEGRATED GEOPHYSICAL CHARACTERIZATION OF FLUIDIZED SEDIMENTS: A CASE STUDY OF FLUID-MUDS AT CASINO BEACH, RIO GRANDE/RS, BRAZIL
} TERNES, C.F ${ }^{1}$; SPERLE, M. ${ }^{2}$; RAMOS, R.R.C. ${ }^{1}$

${ }^{1}$ Universiade Federal do Rio de Janeiro; ${ }^{2}$ Universiade do Estado do Rio de Janeiro.

Copyright 2021, SBGf - Sociedade Brasileira de Geofísica.

This paper was prepared for presentation during the $17^{\text {th }}$ International Congress of the Brazilian Geophysical Society held in Rio de Janeiro, Brazil, 8-11 November 2021.

Contents of this paper were reviewed by the Technical Committee of the $17^{\text {th }}$ International Congress of the Brazilian Geophysical Society and do not necessarily represent any position of the SBGf, its officers or members. Electronic reproduction or storage of any part of this paper for commercial purposes without the written consent of the Brazilian Geophysical Society is prohibited.

\begin{abstract}
The term fluid-muds are given to the layer of fine suspended sediments, located near the seabed, which presents densities close to $1,200 \mathrm{~kg} / \mathrm{m}^{3}$. The episodes of occurrence of fluid mud at Cassino Beach (Rio Grande/RS, Brazil) make up a particular situation, where a layer of recently deposited mud in portions of the inner continental shelf is remobilized during storm events with waves $(3-4 \mathrm{~m})$; being episodically cast onto the beach face. This work is the result of a multidisciplinary study carried out to characterize the mud deposit, covering the relationship between the hydrodynamic and sedimentological aspects and their effects on the beach and the nearshore. In this context, geophysical surveys (echobathymetry, sonography and shallow seismic), geological surveys (sampling of bottom sediments and cores) and rheological surveys (density profiling in water and sediments) were carried out to characterize these mud deposits. By identifying a "double trace" in the $210 \mathrm{kHz}$ echobathymetric record, it was possible to map the fluid mud deposit, as well as its thickness (1-2m), showing the effectiveness of the method for mapping fluid muds on the inner continental shelf. These data were compatible with the data from the densimeter and from the sedimentological samples. After the integration of geological and geophysical data, four distinct acoustic patterns were found, namely: I) Pattern I - indicative of the presence of fluid mud; ii) Pattern II - indicative of the presence of plastic mud; iii) Pattern III - indicative of the presence of sandy-mud and iv) Pattern IV - indicative of the presence of muddy-sand. Several correlation tests were carried out between these patterns and it is concluded that the integration of acoustic geophysical methods, especially the high resolution shallow seismic, with CHIRP Multifrequency technology $(2-16 \mathrm{kHz})$ ) associated with in situ rheological parameters, proved to be very effective and robust for the spatial determination $(x, y, z)$ of fluid-mud deposits. Sonography $(100 / 500 \mathrm{kHz})$ helped in the study of muddy bottoms. However, the use of side scan sonar was not conclusive in the characterization of fluidized sediments. Therefore, the need for the integration of acoustic geophysical data was clearly evidenced, especially the shallow seismic CHIRP-Multifrequency, properly parameterized by geological sampling, for the determination and spatiotemporal characterization of the dynamics of fluid-sludge in coastal and port areas.
\end{abstract}

